\title{
Neurofilament light chain in the vitreous humor of the eye
}

Manju L. Subramanian ${ }^{1 *}$ (D), Viha Vig ${ }^{1}$, Jaeyoon Chung ${ }^{2}$, Marissa G. Fiorello ${ }^{1}$, Weiming Xia ${ }^{3,4}$, Henrik Zetterberg ${ }^{5,6,7,8}$, Kaj Blennow ${ }^{5,6}$, Madeleine Zetterberg ${ }^{9}$, Farah Shareef ${ }^{10}$, Nicole H. Siegel' ${ }^{1}$, Steven Ness ${ }^{1}$, Gyungah R. Jun ${ }^{2}$ and Thor D. Stein ${ }^{11,12,13}$

\begin{abstract}
Background: Neurofilament light chain (NfL) is a promising biomarker of neurodegeneration in the cerebrospinal fluid and blood. This study investigated the presence of NfL in the vitreous humor and its associations with amyloid beta, tau, inflammatory cytokines and vascular proteins, apolipoprotein E (APOE) genotypes, Mini-Mental State Examination (MMSE) scores, systemic disease, and ophthalmic diseases.

Methods: This is a single-site, prospective, cross-sectional cohort study. Undiluted vitreous fluid (0.5-1.0 mL) was aspirated during vitrectomy, and whole blood was drawn for APOE genotyping. NfL, amyloid beta (A $\beta$ ), total Tau (tTau), phosphorylated Tau (p-Tau181), inflammatory cytokines, chemokines, and vascular proteins in the vitreous were quantitatively measured by immunoassay. The main outcome measures were the detection of NfL levels in the vitreous humor and its associations with the aforementioned proteins. Linear regression was used to test the associations of NfL with other proteins, APOE genotypes, MMSE scores, and ophthalmic and systemic diseases after adjustment for age, sex, education level, and other eye diseases.

Results: NfL was detected in all 77 vitreous samples. NfL was not found to be associated with ophthalmic conditions, APOE genotypes, MMSE scores, or systemic disease $(p>0.05)$. NfL levels were positively associated with increased vitreous levels of $A \beta_{40}\left(p=7.7 \times 10^{-5}\right), A \beta_{42}\left(p=2.8 \times 10^{-4}\right)$, and t-tau $\left(p=5.5 \times 10^{-7}\right)$, but not with $p$ tau181 ( $p=0.53$ ). NfL also had significant associations with inflammatory cytokines such as interleukin-15 (IL-15, $p=$ $\left.5.3 \times 10^{-4}\right)$, IL-16 $\left(p=2.2 \times 10^{-4}\right)$, monocyte chemoattractant protein-1 (MCP1, $\left.p=4.1 \times 10^{-4}\right)$, and vascular proteins such as vascular endothelial growth factor receptor-1 (VEGFR1, $\left.p=2.9 \times 10^{-6}\right)$, Vegf-C $\left(p=8.6 \times 10^{-6}\right)$, vascular cell adhesion molecule-1 (VCAM-1, $\left.p=5.0 \times 10^{-4}\right)$, Tie-2 $\left(p=6.3 \times 10^{-4}\right)$, and intracellular adhesion molecular-1 (ICAM-1, $\left.p=1.6 \times 10^{-4}\right)$.

Conclusion: NfL is detectable in the vitreous humor of the eye and significantly associated with amyloid beta, ttau, and select inflammatory and vascular proteins in the vitreous. Additionally, NfL was not associated with patients' clinical eye condition. Our results serve as a foundation for further investigation of NfL in the ocular fluids to inform us about the potential utility of its presence in the eye.
\end{abstract}

Keywords: Alzheimer's disease, Vitreous humor, Neuro-filament light chain, Ocular biomarkers, Amyloid beta, Tau

\footnotetext{
* Correspondence: Manju.Subramanian@bmc.org

'Department of Ophthalmology, Boston Medical Center, Boston University School of Medicine, 85 E Concord St. \#8813, Boston, MA 02118, USA

Full list of author information is available at the end of the article
}

(c) The Author(s). 2020 Open Access This article is licensed under a Creative Commons Attribution 4.0 International License, which permits use, sharing, adaptation, distribution and reproduction in any medium or format, as long as you give appropriate credit to the original author(s) and the source, provide a link to the Creative Commons licence, and indicate if changes were made. The images or other third party material in this article are included in the article's Creative Commons licence, unless indicated otherwise in a credit line to the material. If material is not included in the article's Creative Commons licence and your intended use is not permitted by statutory regulation or exceeds the permitted use, you will need to obtain permission directly from the copyright holder. To view a copy of this licence, visit http://creativecommons.org/licenses/by/4.0/ The Creative Commons Public Domain Dedication waiver (http://creativecommons.org/publicdomain/zero/1.0/) applies to the data made available in this article, unless otherwise stated in a credit line to the data. 


\section{Background}

Neurodegenerative diseases have risen in prevalence over the last few decades with the growth of an aging population in Western society [1]. Of the two most common neurodegenerative diseases, Alzheimer's disease (AD) alone affects 5.5 million Americans while Parkinson's disease (PD) now affects over 1 million individuals in the USA [2]. Although the diagnosis of neurodegenerative diseases is often based on clinical presentation supported by diagnostic testing during later stages, early diagnosis remains a challenge. There is a need for reliable biomarkers that can serve as a mechanism for early diagnosis, prognostic assessment, and measurable response to treatment for AD and other neurological disorders. More recently, neurofilament light chain (NfL), a promising biomarker of neurodegeneration, has been identified in the cerebrospinal fluid (CSF) and blood as a potential screening tool and prognostic indicator, and it may now be on the brink of clinical applicability [3].

NfL is a subunit of neurofilaments (Nfs), which are proteins exclusively located in the neuronal cytoplasm to provide structural stability and maintain the integrity of neurons and speed of impulses. Large axons need and express both NfL and Nfs. Under normal circumstances, $\mathrm{NfL}$ is persistently released at low levels, and with increasing age, higher levels are seen in older individuals [4]. Higher levels of NfL are also seen in both the cerebrospinal fluid (CSF) and blood in those with neurodegenerative, inflammatory, or vascular injury of neurons, in several different neurological diseases, including multiple sclerosis (MS), AD, frontotemporal dementia (FTD), amyotrophic lateral sclerosis (ALS), atypical Parkinsonian disorders (APDs), and traumatic brain injury (TBI). In addition to other biomarkers such as amyloid beta $(A \beta)$ and tau protein, elevated levels of NfL in both the CSF and blood have been shown to differentiate healthy controls from subjects with AD with reliable accuracy [3, 5-9]. Although NfL is not yet being used as a screening tool in the clinical setting, the ability of serum $\mathrm{NfL}$ to detect and differentiate people suffering from neurodegenerative diseases from healthy controls has made it an important research subject in the last few decades [10].

The eye is a window to the brain, and they both share a common embryological origin and vasculature [1117]. Eye diseases such as cataracts, glaucoma, macular degeneration, and diabetic retinopathy have been associated with $\mathrm{AD}$ in epidemiological studies, indicating that eye disease and AD possibly share common risk factors and pathological mechanisms at the molecular level [18-22]. The interconnections between the eye and the brain suggest that elucidating the common features of neurodegenerative processes can lead to a better understanding of both neurological and eye diseases [23].
Recently, we found that cognitive function, measured by Mini-Mental Status Examination (MMSE), in patients with eye disease is significantly associated with the levels of amyloid $\beta\left(A \beta_{40}\right.$ and $\left.A \beta_{42}\right)$ and total tau (t-tau) proteins in the vitreous humor [24]. We now hypothesize that NfL can be identified in the vitreous and associated with other relevant biomarkers of neuronal origin.

\section{Methods}

This was a prospective, cross-sectional cohort study conducted at Boston University Medical Center (BUMC). Approval and oversight for the study protocol were provided by the BUMC Institutional Review Board (study reference number H33883) and was in accordance with the ethical standards of the Committee on Human Experimentation of our institution and the Declaration of Helsinki.

The aim of this study was to detect the presence of NfL in the vitreous humor of the eye and assess its associations with core biomarkers for $\mathrm{AD}\left(\mathrm{A} \beta_{40}, \mathrm{~A} \beta_{42}\right.$, t-tau, and p-tau181), inflammatory and vascular proteins, MMSE scores, apolipoprotein E (APOE) allele status, and ophthalmic and systemic diseases.

Vitreous humor, a gelatinous non-regenerative fluid that fills the posterior segment of the eye, is accessible by needle aspiration in the office setting or by surgery in the operative setting. Study participants were selected based on the following criteria: age 18 years or older, primary language English or Spanish, and those scheduled for pars plana vitrectomy in at least one eye for a clinical eye condition. Surgical indications for vitrectomy included various vitreoretinal disorders, such as rhegmatogenous retinal detachment (R-RD), macular hole $(\mathrm{MH})$, epiretinal membrane (ERM), or complications of diabetic retinopathy (DR) such as vitreous hemorrhage and tractional retinal detachment. Written informed consent was obtained from all patients who participated in the study, and no patients were excluded due to existing ocular or medical comorbidities.

Demographic and clinical data were obtained from patients once enrolled through the completion of a patient questionnaire as well as access to those patients' electronic medical records. Demographic data included race and the highest educational level completed, along with athletic and military history. Clinical information was collected on study participants, including medical and smoking history, history of head and/or neck injuries, family history of cognitive dysfunction, and subjective cognitive complaints. Furthermore, patients' baseline color vision, ocular history, and family history of ocular disease were obtained. All study participants were administered an MMSE within 1 week prior to their eye surgery. 


\section{Biospecimen collection}

Vitreous samples were collected at the start of each vitrectomy procedure by the surgical team, and 0.5-1.0 $\mathrm{mL}$ of undiluted vitreous fluid was aspirated via the vitrectomy probe into an attached sterile $3-\mathrm{mL}$ syringe. Infusion of saline into the vitreous cavity was immediately undertaken in order to re-pressurize the posterior chamber of the eye. The syringe containing the specimen was then capped using a sterile technique and directly handed to a research assistant who labeled it with a predetermined non-identifiable study number and placed the sample on ice for transport. In the Molecular Genetics Core Laboratory (MGCL) at Boston University, the vitreous samples were aliquoted into 900- $\mu$ l Eppendorf tubes and stored at $-80^{\circ} \mathrm{C}$ until analysis. Aside from the collection of the vitreous samples, each study participant's vitrectomy was completed according to the clinical standard of care for that patient's ocular condition.

Blood samples were collected on a separate occasion from all study participants prior to surgery. Eighteen milliliters of whole blood was drawn from each patient into EDTA-treated purple top tubes. The MGCL processed the de-identified blood samples into their component serum, plasma, and buffy coat. The buffy coat was later used for DNA extraction and $A P O E$ genotyping.

\section{Immunoassay measurements for neurofilament light chain}

Vitreous samples were sent to the Institute of Neuroscience and Physiology, Sahlgrenska Academy at the University of Gothenburg in Sweden. Vitreous fluid NfL concentration was measured using the commercially available NF-Light kit on a single-molecule array (Simoa) HD-X Analyzer (Quanterix, Billerica, MA) in one round of experiments using one batch of reagents. Coefficients of variation for QC samples at concentrations of 8.8 and $149 \mathrm{pg} / \mathrm{mL}$ were $2.1 \%$ and $8.9 \%$, respectively.

\section{Immunoassay measurement for amyloid, tau, and inflammatory cytokines, chemokines, and vascular proteins}

Vitreous samples were centrifuged for $15 \mathrm{~min}$ at 12,000 rpm to separate the cellular contents, aliquoted at $100 \mu \mathrm{l}$, frozen at $-80^{\circ} \mathrm{C}$, and then used for $\mathrm{A} \beta$, $\mathrm{t}$-tau, and p-tau181 measurements. Briefly, assays were run per the manufacturer's instructions and in duplicate for beta-amyloid 1-40 and 1-42 (Meso Scale Discovery (MSD), Rockville, MD, \#K15200E-2), tau phosphorylated at threonine 181 (p-tau181), and t-tau (MSD \#K15121D2), using capturing antibody AT270 against p-tau181 (Thermo Scientific \#MN1050) and T46 antibody against total tau as the detecting antibody (Thermo Scientific). Neuroinflammatory cytokines were measured using Neuroinflammation Panel 1 (K15210G, MSD). Samples were diluted 1:2 for pro-inflammatory panel 1 (IFN- $\gamma$, IL10, IL-12p70, IL-13, IL-1 $\beta$, IL-2, IL-4, IL-6, IL-8, TNF- $\alpha$ ), cytokine panel 1 (IL-12/IL-23p40, IL-15, IL-16, IL-17A, IL-1 $\alpha$, IL-5, IL-7, TNF- $\beta$, VEGF-A), and angiogenesis panel 1 (basic FGF, VEGFR-1/Flt-1, Tie-2, VEGF-C, VEGF-D), or 1:5 for vascular injury panel 2 (SAA, CRP, VCAM-1, ICAM-1). Sulfo-tag-conjugated anti-mouse secondary antibody (MSD) was used for signal detection by the MSD platform, and an MSD SECTOR S 600 Imager was used to measure the analyte levels.

\section{Apolipoprotein E genotyping}

DNA was extracted from the buffy coat, and single nucleotide polymorphisms from the APOE gene (National Center for Biotechnology Information SNPs rs429358 and rs7412) were examined using TaqMan assays (Applied Biosystems, Foster City, CA).

\section{Statistical analysis}

Due to the skewed distributions of the levels of NfL and other biomarkers, the protein levels were logtransformed after adding one. We performed association tests on vitreous NfL with vascular/inflammatory-related biomarkers, also in the vitreous, as quantitative outcomes under a linear regression model. We assessed the effects of $A P O E$ genotypes ( $\varepsilon 2$ and $\varepsilon 4$ ), used as predictors, with NfL levels as well as other biomarkers as quantitative outcomes, also using linear regression, with gender and age at the time of the eye exam as covariates. In addition, we conducted an association of NfL levels with MMSE test scores as a quantitative outcome, adjusting for gender, age, and education level as covariates. A term for education level was categorized into three levels, including (1) less than or equal to 8th grade level, (2) 9th grade to high school, and (3) greater than or equal to college (bachelors or associates). The covariate education level was analyzed as an ordinal and categorical variable. $p$ values of less than 0.05 were regarded as statistically significant. Because patients with diabetes are at higher risk for the development of dementia and $\mathrm{AD}$ as well as retinal damage in the eye, we sought to determine vitreous associations independent of diabetes, so our results were adjusted for diabetes. To account for the multiple cytokines and vascular proteins tested, the Bonferroni correction was conducted to determine which ones remained statistically significant. The number of analytes corrected for includes all the proteins tested in this study $(n=41)$, including $\mathrm{NfL}$, resulting in a new $p$ value cutoff of 0.0012 . Additionally, due to our highly diverse patient cohort, NfL levels were compared to race and ethnicity by means of the analysis of variance (ANOVA). 


\section{Results}

The results identified NfL protein in the vitreous humor of all 77 samples from 77 unique subjects. Sixty-three percent of the subjects were male, and the mean age was 56.2 years. The ethnic breakdown of our sample population is a close representation of the patient population typically seen at the eye clinic at BUMC, and $69 \%$ of the sample population were over the age of 50 years (Table 1). The data indicates there were no structural biases in the sample population among disease category, age, gender, race, or educational level. Of the 77 subjects, 55 ( $71.42 \%$ of the cohort) had $20 \mathrm{pg} / \mathrm{mL}$ or more NfL protein present in the vitreous humor. The median NfL level was $68.65 \mathrm{pg} / \mathrm{mL}$, and the mean level was $432.67 \mathrm{pg} / \mathrm{mL} \pm 1124.47 \mathrm{pg} / \mathrm{mL}$, a large difference due to the skewed distribution in the raw data. But after the NfL values were transformed via quality control and $\log _{2}$ transformation, NfL proteins were found to have a normal distribution in the vitreous humor (Fig. 1).

Further analysis found statistically significant associations between the levels of NfL and $\mathrm{A} \beta_{40}$ ( $p$ value $=$ $\left.7.7 \times 10^{-5}\right), \quad \mathrm{A}_{42} \quad\left(p=2.8 \times 10^{-4}\right)$, and $\mathrm{t}$-tau $(p=5.5 \times$ $10^{-7}$ ) in the vitreous humor, with higher levels of NfL being associated with higher levels of all three biomarkers (Fig. 2a-c and Table 2). All three biomarkers maintained statistical significance after removing values from the analysis that appeared to be outliers (Supplemental Figure 1). Additionally, we found the concentration of NfL in the vitreous has significant associations with inflammatory cytokines and vascular proteins in the vitreous, specifically IL-15 $\left(p=5.3 \times 10^{-4}\right)$, IL-16 ( $p=$ $\left.2.2 \times 10^{-4}\right)$, MCP-1 $\left(p=4.1 \times 10^{-4}\right)$, VEGFR-1 $(p=2.9 \times$ $\left.10^{-6}\right)$, Vegf-C $\left(p=8.6 \times 10^{-6}\right)$, VCAM-1 $\left(p=5.0 \times 10^{-4}\right)$, Tie-2 $\left(p=6.3 \times 10^{-4}\right)$, and ICAM-1 $\left(p=1.6 \times 10^{-4}\right)$ (Table 3). Many of the biomarkers maintained their significant associations after adjusting for diabetes and after conducting the Bonferroni correction for multiple comparisons. Mean and SD values of NfL and all biomarkers tested in the vitreous humor are presented in Supplemental Table 1, Additional file 1.

Our data also shows that NfL in the vitreous humor was not associated with patients' clinical eye diagnoses or systemic diseases such as hypertension, diabetes, and hyperlipidemia (Table 4). We also found that NfL was not significantly associated with $A P O E$ genotypes $\varepsilon 2$ and $\varepsilon 4$ (Supplemental Table S2, Additional file 2 and Fig. 3), which are the 2 alleles most commonly associated with AD. Furthermore, there were no statistically significant associations of NfL with MMSE scores (Supplemental Table S3, Additional file 3). Additionally, there was no significant correlation between NfL levels in the vitreous humor and patients' race or ethnicity in our sample population (Supplemental Figures 2 and 3).

\section{Discussion}

Our study identified and quantified NfL in the vitreous humor of the eye and showed that NfL is positively associated with levels of $A \beta_{40}, A \beta_{42}$, and t-tau and other select inflammatory cytokines. Notably, NfL levels were not significantly associated with eye disease, so the levels of NfL in the vitreous humor do not appear to be influenced by the patients' clinical eye condition(s). In addition, NfL levels were not associated with APOE genotypes, and we did not find a significant association with systemic diseases such as diabetes.

Most current studies investigating the role of the eye in neurodegenerative disease, such as $\mathrm{AD}$, focus on retinal biomarkers imaged by optical coherence tomography (OCT). For example, the retinal nerve fiber layer (RNFL) is thinner, the retinal volume is reduced, and the choroidal thickness is reduced in patients with mild cognitive impairment (MCI) and $\mathrm{AD}$ compared to cognitively normal $(\mathrm{CN})$ controls [25-38]. A newer and more sophisticated version of the OCT, the optical coherence tomography angiography (OCTA), has shown significant changes to the superficial and deep capillary vascular plexus of the macula and changes to the foveal avascular zone in those with cognitive dysfunction and AD compared to CN controls [39-49]. However, data obtained by OCT/OCTA, while promising, have shown conflicting results and can be confounded by the presence of co-existing eye disease and systemic diseases, such as diabetes, as well as variations in cell layer measurements by different automated platforms [50]. To illustrate this, patients in our study underwent OCT, however, the data was not useful because the patients' eye diseases, such as diabetic retinopathy, retinal detachment, macular holes, or epiretinal membranes, affected the macular cell layer thickness and volume. Therefore, an additional source of biomarkers, such as one that is quantifiable and proteinbased within eye fluid, may potentially offer a more specific marker that may be predictive for neurodegenerative disease.

Current biomarkers for AD comprise 3 categoriesamyloid deposition (A), tau pathology (T), and neurodegeneration $(\mathrm{N})$, known as $\mathrm{A} / \mathrm{T} / \mathrm{N}$ biomarkers [51]. "A" signifies changes on amyloid positron emission tomography (PET) imaging and cerebrospinal fluid (CSF) levels of amyloid beta (A $\beta 1-42)$; "T" indicates biomarkers of tau, including tau PET or CSF phosphorylated tau (ptau); and "N" stands for neurodegeneration as reflected by CSF total tau (t-tau), F-2-fluoro-2-deoxy-d-glucose PET (FDG-PET), and pathological findings on magnetic resonance imaging (MRI). The clinical utility and diagnostic potential of the core CSF biomarkers for $\mathrm{AD}$ $\left(\mathrm{A} \beta_{40}, \mathrm{~A} \beta_{42}\right.$, p-tau, and $\mathrm{t}$-tau) are well known and indisputable. However, since access to CSF is more invasive than access to the blood, the utility of testing CSF for 
Table 1 Patient demographics and overall sample breakdown

\begin{tabular}{|c|c|}
\hline Characteristic & Overall sample breakdown $(N=77)$ \\
\hline \multicolumn{2}{|l|}{ Sex } \\
\hline Male & $49(63.63 \%)$ \\
\hline Female & $28(36.36 \%)$ \\
\hline \multicolumn{2}{|l|}{ Age } \\
\hline Mean age \pm SD & $56.21 \pm 15.52$ \\
\hline Age $>40$ & $68(88.31 \%)$ \\
\hline Age $>50$ & $53(68.83 \%)$ \\
\hline Age $>60$ & $35(45.45 \%)$ \\
\hline \multicolumn{2}{|l|}{ Race } \\
\hline Asian & $3(3.90 \%)$ \\
\hline $\begin{array}{l}\text { American Indian } \\
\text { or Alaskan Native }\end{array}$ & $2(2.60 \%)$ \\
\hline Black or African & $27(35.06 \%)$ \\
\hline Hispanic & $11(14.29 \%)$ \\
\hline White & $26(33.77 \%)$ \\
\hline Others & $8(10.39 \%)$ \\
\hline \multicolumn{2}{|l|}{ Ethnicity } \\
\hline Hispanic & $20(25.97 \%)$ \\
\hline Not Hispanic & $57(74.03 \%)$ \\
\hline \multicolumn{2}{|l|}{ Education level } \\
\hline 8th grade or less & $11(14.29 \%)$ \\
\hline High school & $28(36.36 \%)$ \\
\hline College or greater & $38(49.35 \%)$ \\
\hline \multicolumn{2}{|l|}{ Eye disease category } \\
\hline Age-related macular degeneration & $4(5.19 \%)$ \\
\hline Diabetic retinopathy & $35(45.45 \%)$ \\
\hline Age-related cataracts & $66(85.71 \%)$ \\
\hline Glaucoma & $10(12.99 \%)$ \\
\hline Epiretinal membrane & $17(22.08 \%)$ \\
\hline Retinal detachment & $32(41.56 \%)$ \\
\hline Macular hole & $12(15.58 \%)$ \\
\hline APOE allele & $\begin{array}{l}\text { Overall sample breakdown } \\
\text { ( } n=76,152 \text { alleles) }\end{array}$ \\
\hline $\begin{array}{l}\varepsilon 2 \text { (may offer some protection } \\
\text { against } A D \text { ) }\end{array}$ & $15(9.87 \%)$ \\
\hline$\varepsilon 3$ (neutral risk for $A D$ ) & $121(79.61 \%)$ \\
\hline $\begin{array}{l}\varepsilon 4 \text { (increases risk for } A D \text { at an } \\
\text { earlier age) }\end{array}$ & $16(10.52 \%)$ \\
\hline APOE genotype & $\begin{array}{l}\text { Overall sample breakdown } \\
(n=77)\end{array}$ \\
\hline$\varepsilon 22$ & $0(0.0 \%)$ \\
\hline$\varepsilon 23$ & $11(14.29 \%)$ \\
\hline$\varepsilon 24$ & $4(5.19 \%)$ \\
\hline$\varepsilon 33$ & 45 (58.44\%) \\
\hline$\varepsilon 34$ & $16(20.78 \%)$ \\
\hline$\varepsilon 44$ & $0(0.0 \%)$ \\
\hline
\end{tabular}

Table 1 Patient demographics and overall sample breakdown (Continued)

\begin{tabular}{ll}
\hline MMSE scores, mean \pm SD & Mean \pm SD $(\boldsymbol{n}=\mathbf{7 7})$ \\
No cognitive impairment $(n=68)$ & $27.91 \pm 1.68$ \\
$\begin{array}{l}\text { Mild or severe cognitive } \\
\text { impairment }(n=9)\end{array}$ & $19.44 \pm 2.35$ \\
\hline APOE apolipoprotein E &
\end{tabular}

the screening of neurodegenerative diseases is limited [52]. Recent data suggest a role for the same protein biomarkers in the blood (plasma or serum), in particular the $A \beta 42 / 40$ ratio and $p$-tau 181 , may be clinically meaningful $[53,54]$. Multiple studies have also shown NfL to be significantly associated with more specific biomarkers for AD, particularly tau protein [55-62].

Our study is the first to identify NfL in the vitreous and demonstrate a significant association with $A \beta_{40}$, $\mathrm{A} \beta_{42}$, and $\mathrm{t}$-tau; select vitreous cytokines; and proteins, and also the first to establish that NfL is not associated with patients' local eye condition. However, our results do not show reliable evidence that vitreous NfL levels definitively represent neurodegeneration, and further study is needed to validate NfL in the eye fluid to other established biomarkers of neurodegeneration, such as those found in the CSF or on MRI and PET scan.

The source of elevated NfL in the vitreous humor is unclear. Several pre-clinical studies have shown reduced levels of NfL in the ganglion cell layer of the retina and optic nerve in response to induced injury or ischemia [63-67]. Another study found levels of NfL in the CSF predicted visual outcomes after optic neuritis [68]. Based on this, we can hypothesize that injury, inflammation, or ischemia, from conditions such as glaucoma or optic neuritis which are known to degrade axons in the nerve fiber layer of the retina, results in the local release of NfL from the axons that may diffuse into the vitreous humor through the internal limiting membrane of the retina, leading to elevated NfL in the vitreous. In our cohort, we found no association of elevated NfL levels with eye disease or systemic disease, even in the limited number of patients (13\%) who have known local neurodegenerative conditions such as glaucoma [69]. The lack of association with known eye disease indicates another mechanism may be responsible for the elevated levels of NfL in the vitreous.

$\mathrm{NfL}$ and $\mathrm{t}$-tau are both known biomarkers for neurodegeneration in the CSF and blood [59]. Since NfL and $\mathrm{t}$-tau are both released from axons as a result of axonal degeneration, the positive correlation we found in the vitreous is consistent with what is seen in the brain and CSF. However, studies have not shown a significant relationship between systemic NfL and systemic amyloid beta proteins $\left(A \beta_{40}, A \beta_{42}\right)$ in the CSF or plasma, most likely due to the difficulty with measuring $A \beta$, which is 


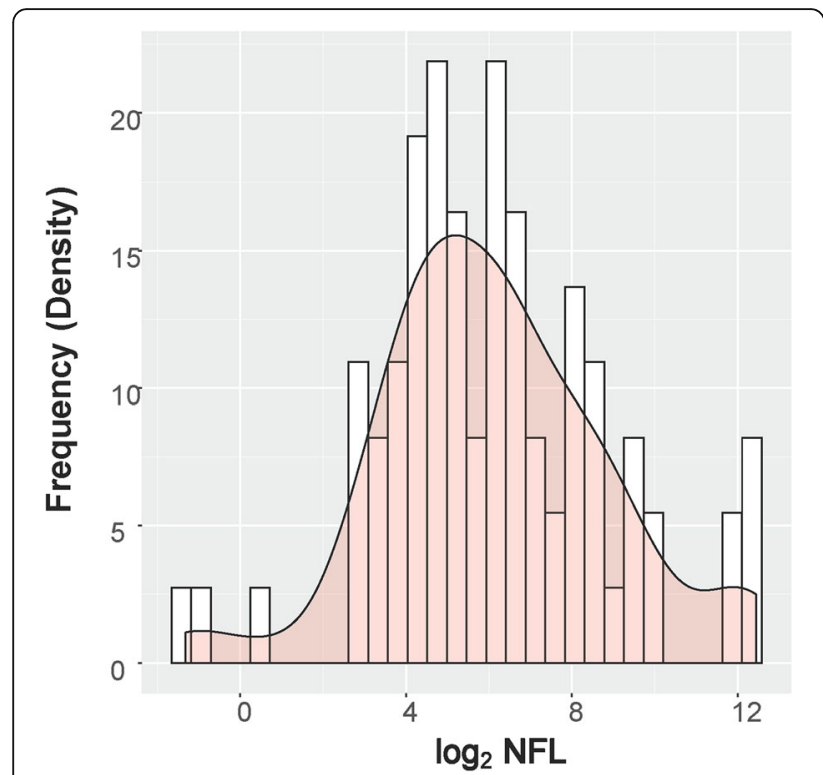

Fig. 1 Normal distribution of Nfl. Distribution of neurofilament light chain levels in the vitreous humor after $\log _{2}$ transformation

derived from the central nervous system, in the blood. The positive association of NfL and $A \beta$ seen in the vitreous humor in our study may be due to a greater ease in testing for $A \beta$ in the vitreous over blood, or possibly an alternative local source of amyloid beta proteins in the eye possibly independent of the amyloid plaques found in the brain [58]. A few pre-clinical mouse studies have indicated that elevated levels of amyloid proteins in the retina and posterior chamber of the eye could be the result of early presymptomatic $\mathrm{AD}$ in mice $[70,71]$.

Our data also showed that NfL was significantly associated with some pro-inflammatory cytokines, chemokines, and vascular injury-related markers in the vitreous humor, and these associations remained significant after adjusting for the presence of diabetes and applying the Bonferroni correction for multiple comparisons (Table 3). As far as we are aware, no prior studies have investigated the association of these inflammatory and vascular proteins with NfL in the CSF, blood, or vitreous humor. But several studies have shown elevated levels of pro-inflammatory cytokines and chemokines in the CSF and blood when the brain experiences neuronal injury, trauma, or neurodegeneration [72-77]. Similarly, microvascular injury biomarkers such as vascular cell adhesion molecule-1 (VCAM-1) and intracellular adhesion molecule-1 (ICAM-1) are released during global and regional cerebral hypoperfusion, a phenomenon associated with neurodegenerative diseases like AD [78]. There is limited research on the diagnostic applicability and clinical utility of these biomarkers, and their significant association with vitreous NfL found in our study indicates further investigation of the interaction of these proteins would increase our understanding of their contribution to pathology.

The clinical utility of obtaining vitreous samples as a possible source of diagnostic testing for $\mathrm{AD}$ should be addressed. Obtaining samples of vitreous fluid can be done in 2 ways, through office-based needle aspiration when up to $100 \mu \mathrm{L}$ can be removed or in the operating room where almost $1 \mathrm{~mL}$ of undiluted vitreous can be safely removed. Our study obtained vitreous fluid on patients requiring surgery for a clinical eye condition, and in this setting, it was safe and easy to obtain. However, similar to lumbar puncture for CSF procurement, obtaining vitreous samples for diagnostic testing and screening universally would not be practical nor costeffective. Investigation of NfL in other eye fluids, such as aqueous humor or tear secretions, could offer a less invasive and more accessible means of fluid collection that could be applied broadly.

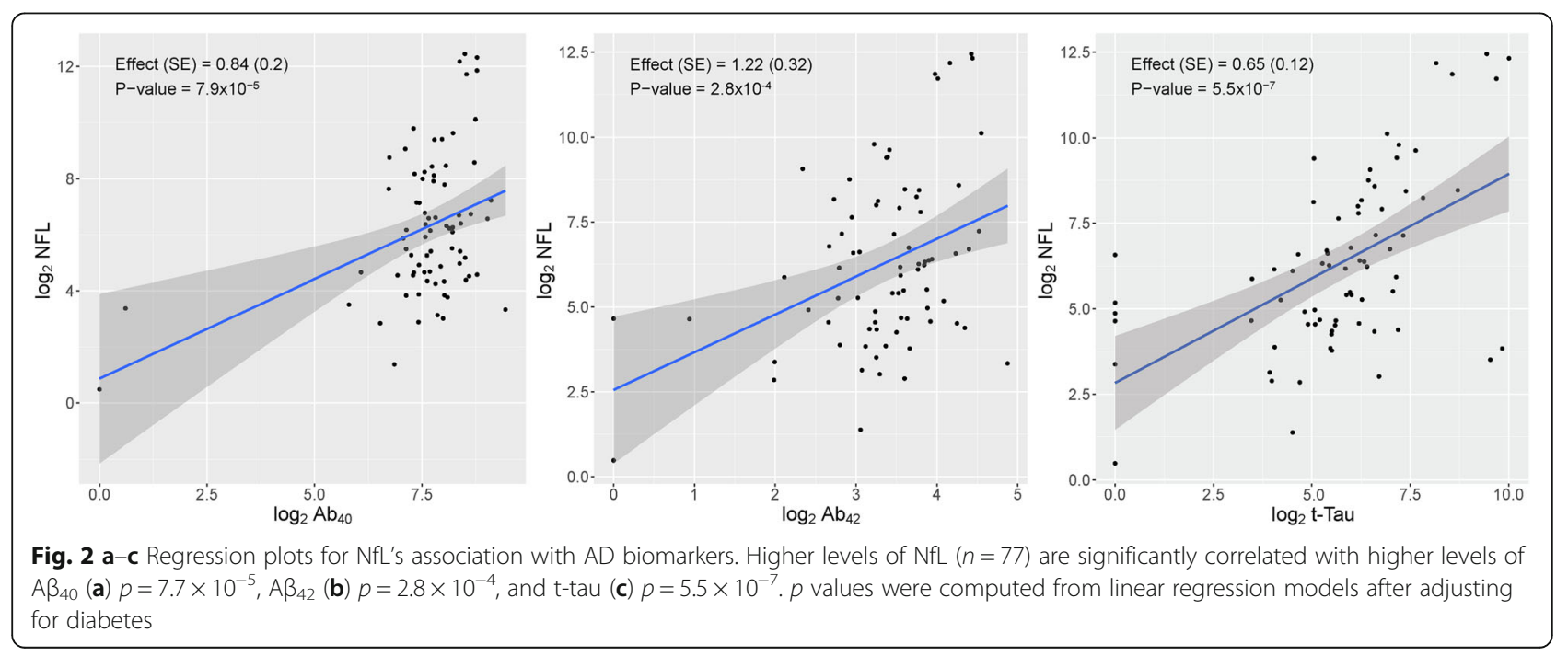


Table 2 Vitreous NfL levels vs. amyloid beta and tau proteins

\begin{tabular}{lllll}
\hline Protein & Beta & SE & $\boldsymbol{p}$ value $(\boldsymbol{n}=\mathbf{7 7})$ & $\boldsymbol{p}$ value (adjusting for DM, $\boldsymbol{n}=\mathbf{7 7})$ \\
\hline $\mathrm{A} \beta_{40}$ & 0.84 & 0.20 & 0.000079 & 0.0000484 \\
$\mathrm{~A} \beta_{42}$ & 1.22 & 0.32 & 0.00028 & 0.00011 \\
t-tau & 0.65 & 0.12 & 0.00000055 & 0.00000021 \\
p-tau 181 & -0.30 & 0.48 & 0.530 & 0.646
\end{tabular}

Associations of $\mathrm{NfL}$ with core protein biomarkers for $\mathrm{AD}$ in the vitreous humor. As diabetic patients are at higher risk for the development of $\mathrm{AD}$ as well as retinal damage, we sought to determine vitreous associations independent of the presence of diabetes, and the significant associations were maintained after adjusting for diabetes

\section{Limitations}

This study had some limitations. While levels of NfL were associated with $A \beta_{40}, A \beta_{42}$, and t-tau, NfL was not significantly associated with MMSE scores. This may be because testing was done in a non-dementia or non-
MCI cohort. MMSE is a crude measurement of cognitive function, and while it is highly specific and valid in the detection of moderate dementia, in mild dementia, it is only 55\% sensitive [79]. MMSE was also checked crosssectionally, and our intent to correlate scores with NfL

Table 3 Association of vitreous NfL levels vs. vitreous levels of inflammatory cytokines and vascular proteins

\begin{tabular}{|c|c|c|c|c|}
\hline Protein & Beta & $S E$ & $p$ value $(n=77)$ & $p$ value (adjusting for $\mathrm{DM}$ ) \\
\hline \multicolumn{5}{|c|}{ Pro-inflammatory cytokines } \\
\hline IL1a & -1.43 & 0.64 & 0.029 & 0.044 \\
\hline $\operatorname{IL} 1 \beta$ & 0.59 & 2.14 & 0.783 & 0.846 \\
\hline IL6 & 0.23 & 0.11 & 0.045 & 0.057 \\
\hline$* \mid L 15$ & 1.21 & 0.33 & 0.000525 & 0.00108 \\
\hline *IL16 & 0.86 & 0.22 & 0.00022 & 0.00044 \\
\hline IL17a & 1.01 & 0.45 & 0.027 & 0.027 \\
\hline TNF-a & 0.20 & 0.61 & 0.748 & 0.645 \\
\hline IFN- $\gamma$ & 0.32 & 0.30 & 0.291 & 0.289 \\
\hline \multicolumn{5}{|c|}{ Anti-inflammatory cytokines } \\
\hline IL4 & 0.83 & 0.60 & 0.17 & 0.20 \\
\hline IL10 & 1.22 & 0.67 & 0.07 & 0.053 \\
\hline IL13 & 0.73 & 0.55 & 0.19 & 0.29 \\
\hline TNF $\beta$ & 0.99 & 1.84 & 0.59 & 0.778 \\
\hline \multicolumn{5}{|c|}{ Chemokines and inflammatory proteins } \\
\hline${ }^{*} \mathrm{MCP}-1$ & 0.63 & 0.17 & 0.000414 & 0.000337 \\
\hline 3MIP1a & 0.19 & 0.14 & 0.155 & 0.153 \\
\hline \multicolumn{5}{|c|}{ Vascular proteins } \\
\hline *VEGFR1 & 0.90 & 0.17 & 0.00000285 & 0.00000292 \\
\hline VEGF-human & 0.23 & 0.10 & 0.027 & 0.046 \\
\hline *Vegf-C & 0.33 & 0.07 & 0.0000086 & 0.0000139 \\
\hline Vegf-D & 0.19 & 0.08 & 0.018 & 0.034 \\
\hline *VCAM-1 & 0.40 & 0.11 & 0.0005 & 0.0007 \\
\hline *Tie2 & 0.25 & 0.07 & 0.00063 & 0.0012 \\
\hline$*$ ICAM-1 & 0.59 & 0.15 & 0.00016 & 0.00028 \\
\hline CRP & 0.23 & 0.10 & 0.0265 & 0.0435 \\
\hline SAA & 0.14 & 0.06 & 0.017 & 0.0289 \\
\hline bFGF & 0.05 & 0.11 & 0.616 & 0.462 \\
\hline
\end{tabular}

Association of NfL with inflammatory cytokines, chemokines, and vascular proteins associated with neurodegenerative disease. The proteins marked with an asterisk $\left(^{*}\right)$ maintain statistical significance with $\mathrm{NfL}$ after conducting the Bonferroni test for multiple comparisons $(0.05 / 41$ analytes with a new $p=0.0012)$. As diabetic patients are at higher risk for the development of $A D$ as well as retinal damage, we sought to determine vitreous associations independent of the presence of diabetes 
Table 4 Eye and systemic disease and NfL levels

\begin{tabular}{|c|c|c|c|c|}
\hline Predictor & Beta & $S E$ & $t$ & $p$ value \\
\hline Macular degeneration & -1.06 & 1.38 & -0.77 & 0.44 \\
\hline Diabetic retinopathy (DR) & 0.45 & 0.61 & 0.74 & 0.46 \\
\hline Age-related cataract (ARC) & 1.21 & 1.01 & 1.19 & 0.24 \\
\hline$A R C+D R$ & 0.22 & 0.61 & 0.36 & 0.72 \\
\hline Cataract surgery & -0.32 & 0.68 & -0.47 & 0.64 \\
\hline Glaucoma & -0.61 & 0.90 & -0.68 & 0.50 \\
\hline Epiretinal membrane & -1.20 & 0.74 & -1.62 & 0.11 \\
\hline Retinal detachment & -0.29 & 0.67 & -0.43 & 0.67 \\
\hline Macular hole & -0.15 & 0.84 & -0.17 & 0.86 \\
\hline Proliferative diabetic retinopathy (stage 4 DR vs. no DR) & 0.45 & 0.62 & 0.73 & 0.47 \\
\hline Hypertension & 0.28 & 0.70 & 0.40 & 0.69 \\
\hline Diabetes & 0.62 & 0.61 & 1.01 & 0.31 \\
\hline Hyperlipidemia & -0.034 & 0.63 & -0.05 & 0.96 \\
\hline
\end{tabular}

No significant association was found between vitreous NfL and the various ophthalmic and systemic diseases in this patient population ( $p>0.05$ )

levels was exploratory; further testing with MMSE longitudinally may shed light on whether NfL in the vitreous is predictive for eventual cognitive decline. Additionally, since no patients in the study carried a diagnosis of $\mathrm{AD}$, validation studies are needed to compare vitreous levels of NfL in patients with MCI or AD to normal controls. This study is the first to investigate the presence of NfL in the vitreous humor by obtaining vitreous samples during surgery. Therefore, a replication sample was not feasible. Furthermore, CSF and blood levels of NfL $\mathrm{A} \beta 40, \mathrm{~A} \beta 42$, and $\mathrm{t}$-tau were not obtained, so we were unable to study its correlation and discriminate vitreous levels with CSF and serum levels in order to compare it with established biomarkers of neurodegenerative disease. Further study on this will be very useful in assessing the utility of NfL in the eye fluid. Another limitation was the variance in ocular and systemic comorbidities among study participants. While our analyses found no significant correlation between NfL and co-existing eye conditions, or systemic conditions such as diabetes, a variety of systemic diseases associated with ocular findings are known to affect cognition. For example, diabetes has been shown to lower cognitive health, increase the risk for development of $\mathrm{AD}$, and release inflammatory cytokines and vascular proteins. On the other hand, diabetic patients are at significant risk for the development of dementia-related to vascular disease and $\mathrm{AD}$, and identifying early markers in the eye may be useful for monitoring this population. Comparing the results of this study to a similar study conducted

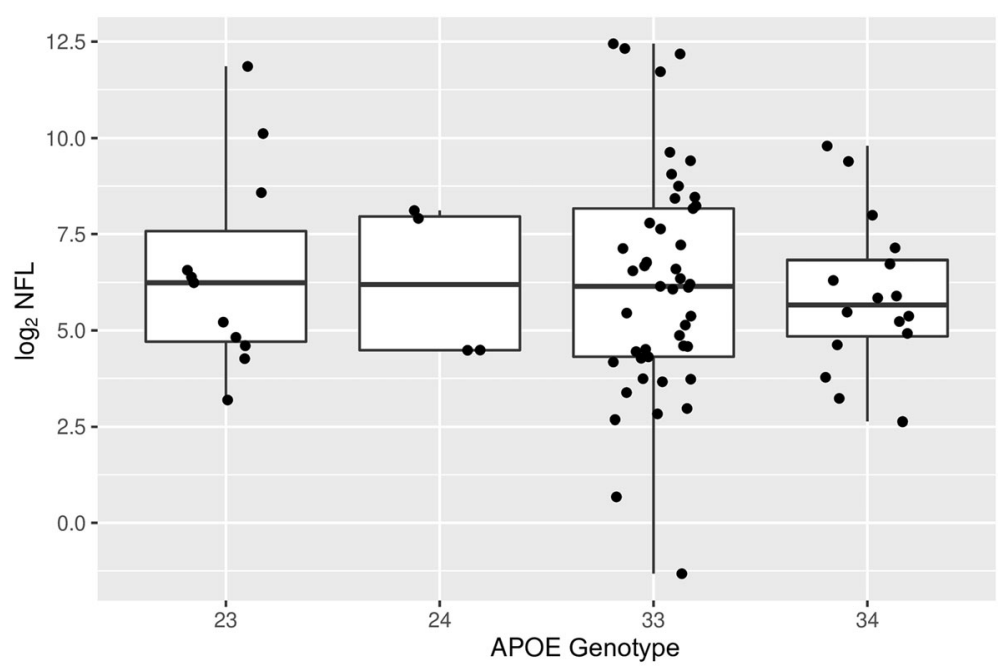

Fig. 3 Boxplot of NfL with APOE genotype obtained from the subjects' blood. No significant association is observed between APOE alleles 23, 23, 33, and 34, with vitreous NfL levels 
on a patient population suffering from $A D$ and other types of neurodegenerative disorders will give us a more comprehensive understanding of how this biomarker in the vitreous can contribute as a diagnostic measure.

\section{Conclusion}

In summary, we identified and quantified NfL in the vitreous humor of the eye and significantly associated those levels with proteins such as $A \beta_{40}, A \beta_{42}$, and $t$-tau, and select cytokines and vascular proteins, and established that NfL levels were not influenced by the patients' clinical eye conditions. These 2 findings are foundational for future studies evaluating the potential utility of NfL in the eye.

\section{Supplementary information}

Supplementary information accompanies this paper at https://doi.org/10. 1186/s13195-020-00677-4.

Additional file 1: Supplemental Table S1. Immunoassay Results of all Protein Biomarkers Measured in the Vitreous Humor. The table shows the mean, median, standard deviation and interquartile range of all the proteins measured in the vitreous humor

Additional file 2: Supplemental Table S2. Summary statistics of association between NfL Levels with APOE genotype. The table indicates no significant association was found between vitreous NfL levels APOE genotypes $\varepsilon 2$ and $\varepsilon 4$.

Additional file 3: Supplemental Table S3. Association of NfL Levels with MMSE Scores. The table indicates no significant association was found between vitreous NfL levels and MMSE score; covariates are age, sex and education level.

Additional file 4: Supplemental Figure S1. Regression plots for NfL association with AD biomarkers after removal of outliers. Legend: Higher levels of NfL levels are significantly correlated with higher levels of $A \beta_{40}$ ( $3 \mathrm{a}, n=74$ with $\left.p=4.9 \times 10^{-3}\right), A \beta_{42}\left(3 \mathrm{~b}, n=73\right.$ with $\left.p=5.4 \times 10^{-3}\right)$, and t-tau ( $3 c, n=68$ with $p=9.0 \times 10^{-8}$ ). The significance slope is steeper with a higher $p$-value for t-tau's association with $\mathrm{NfL}$ (3c compared to $2 \mathrm{c}$ ), after removal of the outliers. $P$ values were computed from linear regression models after adjusting for diabetes.

Additional file 5: Supplemental Figure S2. Association of NfL Levels with Race. Description of Data: This figure shows no significant association was found between vitreous NfL levels and Race.

Additional file 6: Supplemental Figure S3. Association of NfL Levels with Ethnicity. This figure shows no significant association was found between vitreous NfL levels and Ethnicity.

\section{Abbreviations}

NfL: Neurofilament light chain; AD: Alzheimer's disease; A MMSE: Mini-Mental State Examination; APOE: Apolipoprotein E; IL: Interleukin; MCP-1: Monocyte chemoattractant protein-1; VEGFR1: Vascular endothelial growth factor receptor 1; Vegf: Vascular endothelial growth factor; VCAM1: Vascular cell adhesion protein 1; ICAM-1: Intercellular adhesion molecule 1 ; MIP1a: Macrophage inflammatory protein-1 alpha; CRP: C-reactive protein; SAA: Serum amyloid A; bFGF: Basic fibroblast growth factor; TNF-a: Tumor necrosis factor alpha; IFN- $\gamma$ : Interferon gamma; PD: Parkinson's Disease; CSF: Cerebrospinal fluid; MS: Multiple sclerosis; FTD: Frontotemporal dementia; ALS: Amyotrophic lateral sclerosis; APD: Atypical Parkinsonian disorders; TBI: Traumatic brain injury; ARC: Age-related cataract; RRD: Rhegmatogenous retinal detachment; $\mathrm{MH}$ : Macular hole; ERM: Epiretina membrane; VH: Vitreous hemorrhage; T-RD: Tractional retinal detachment; DR: Diabetic retinopathy; MGCL: Molecular Genetics Core Laboratory; Simoa: Single-molecule array; MSD: Meso Scale Discovery; OCT: Optical coherence tomography; RNFL: Retinal nerve fiber layer; MCl: Mild cognitive impairment; CN: Cognitively normal; OCTA: Optical coherence tomography angiography; PET: Positron emission tomography; p-tau: Phosphorylated tau; t-tau: Total tau; FDG-PET: F-2-fluoro-2-deoxy-d-glucose PET; SE: Standard error

\section{Acknowledgements}

The family of James Hamblett whose yearly donations supported this research effort. We would also like to acknowledge Kelley Turner and Kate McConnell for their contribution to this study.

\section{Authors' contributions}

MLS is the principal investigator and the corresponding author. MLS was responsible for the study conception and design, performed the vitrectomy surgery, collected the vitreous humor samples during surgery, interpreted the data regarding $\mathrm{NfL}$ and its associations with $\mathrm{AD}$ pathological proteins in the vitreous humor, and drafted and critically revised the manuscript. W interpreted the data regarding NfL and its associations, prepared the tables, and drafted and revised the manuscript. JC performed the statistical analysis for this study including quality control and regression analysis. JC wrote the "Statistical analysis" section under the "Methods" section, created the figures, and revised the manuscript. MGF was involved with patient enrolment and consent, sample collection during surgery, data entry and dataset management, project coordination, and manuscript revision. WX conducted the immunoassays for amyloid beta, tau, inflammatory, and vascular proteins levels in the vitreous humor and genotype testing of blood samples. $\mathrm{HZ}$ and $\mathrm{KB}$ conducted the ELISA NfL protein biomarker analysis on all samples and assisted with the manuscript revisions and final approval. MZ contributed to the validation of the NfL assay for the vitreous, on all samples, and assisted with the manuscript revisions. FS drafted the manuscript and participated in the manuscript revisions and final approval. NHS and SN performed the vitrectomy surgery, collected the vitreous humor specimen during surgery, and contributed to the manuscript revisions and final approval. GRJ contributed to the initial study conception and design, manuscript revisions, and approval. TDS contributed to the study conception and design, aided in the immunoassays of proteins in the vitreous humor and genotype testing in blood samples, contributed to the interpretation of the data and its associations with AD pathological proteins, and critically revised and approved the manuscript. The author(s) read and approved the final manuscript.

\section{Funding}

1) Dr. Manju L. Subramanian (MLS): National Institute of Aging (R03AG063255); the family of James Hamblett with yearly donations to support the research efforts of MLS.

2) Dr. Thor Stein: Department of Veterans Affairs, Clinical Sciences Research and Development Merit Award (I01-CX001038); National Institute of Aging (RF1AG054156).

3) $\mathrm{HZ}$ is a Wallenberg Scholar supported by grants from the Swedish Research Council (\#2018-02532); the European Research Council (\#681712); Swedish State Support for Clinical Research (\#ALFGBG-720931); the Alzheimer Drug Discovery Foundation (ADDF), USA (\#201809-2016862); and the UK Dementia Research Institute at UCL.

4) KB is supported by the Swedish Research Council (\#2017-00915); the Alzheimer Drug Discovery Foundation (ADDF), USA (\#RDAPB-2018092016615); the Swedish Alzheimer Foundation (\#AF-742881); Hjärnfonden, Sweden (\#FO2017-0243); the Swedish state under the agreement between the Swedish government and the County Councils, the ALF-agreement (\#ALFGBG-715986); and the European Union Joint Program for Neurodegenerative Disorders (JPND2019-466-236).

The sponsor or funding organization had no role in the design or conduct of this research.

\section{Availability of data and materials}

All data generated or analyzed during this study are included in the published article and its supplementary information files.

\section{Ethics approval and consent to participate}

Approval and oversight for the study protocol were provided by the BUMC Institutional Review Board and was in accordance with the ethical standards of the Committee on Human Experimentation of our institution and the Declaration of Helsinki. 


\section{Consent for publication}

Not applicable

\section{Competing interests}

Henrik Zetterberg $(H Z)$ has served at the scientific advisory boards for Denali, Roche Diagnostics, Wave, Samumed, and CogRx; has given lectures in symposia sponsored by Fujirebio, Alzecure, and Biogen; and is a co-founder of Brain Biomarker Solutions in Gothenburg AB (BBS), which is a part of the GU Ventures Incubator Program. Kaj Blennow has served as a consultant at the advisory boards or at the data monitoring committees for Abcam, Axon, Biogen, Julius Clinical, Lilly, MagQu, Novartis, Roche Diagnostics, and Siemens Healthineers, and is a co-founder of Brain Biomarker Solutions in Gothenburg $A B(B B S)$, which is a part of the GU Ventures Incubator Program. The other authors have no conflict of interest to report.

\section{Author details}

'Department of Ophthalmology, Boston Medical Center, Boston University School of Medicine, 85 E Concord St. \#8813, Boston, MA 02118, USA. ${ }^{2}$ Department of Medicine (Biomedical Genetics Section), Boston University School of Medicine, Boston, MA, USA. ${ }^{3}$ Department of Pharmacology and Experimental Therapeutics, Boston University School of Medicine, Boston, MA, USA. ${ }^{4}$ Geriatric Research Education and Clinical Center, Bedford Veterans Affairs Medical Center, Bedford, MA, USA. ${ }^{5}$ Department of Psychiatry and Neurochemistry at Institute of Neuroscience and Physiology, Sahlgrenska Academy at University of Gothenburg, Gothenburg, Sweden. ${ }^{6} \mathrm{Clinical}$ Neurochemistry Laboratory, Sahlgrenska University Hospital, Mölndal, Sweden. ${ }^{7}$ Department of Neurodegenerative Diseases, UCL Institute of Neurology, London, UK. ${ }^{8}$ UK Dementia Research Institute at UCL, London, UK. ${ }^{9}$ Department of Clinical Neuroscience at Institute of Neuroscience and Physiology, Sahlgrenska Academy at University of Gothenburg, Gothenburg, Sweden. ${ }^{10}$ Department of Ophthalmology, University of Illinois at Chicago School of Medicine, Chicago, IL, USA. ${ }^{11}$ Boston University Alzheimer's Disease and CTE Center, Boston University School of Medicine, Boston, MA, USA.

${ }^{12}$ Department of Pathology and Laboratory Medicine, Boston Medical Center, Boston University School of Medicine, Boston, MA, USA. ${ }^{13}$ Department of Veterans Affairs Medical Center, VA Boston Healthcare System, Boston, MA, USA.

Received: 15 June 2020 Accepted: 1 September 2020 Published online: 17 September 2020

\section{References}

1. Hou Y, Dan X, Babbr M, et al. Ageing as a risk factor for neurodegenerative disease. Nat Rev Neurol. 2019;15(10):565-81. https://doi.org/10.1038/s41582019-0244-7.

2. Erkkinen MG, Kim MO, Geschwind MD. Clinical neurology and epidemiology of the major neurodegenerative diseases. Cold Spring Harb Perspect Biol. 2018;10(4):a033118. Published 2018 Apr 2. https://doi.org/10.1101/ cshperspect.a033118.

3. Gaetani L, Blennow K, Calabresi P, Di Filippo M, Parnetti L, Zetterberg H. Neurofilament light chain as a biomarker in neurological disorders. J Neurol Neurosurg Psychiatry. 2019 Aug;90(8):870-81. https://doi.org/10.1136/jnnp2018-320106.

4. Disanto G, Barro $C$, Benkert $P$, et al. Serum neurofilament light: a biomarker of neuronal damage in multiple sclerosis. Ann Neurol. 2017;81(6):857-70. https://doi.org/10.1002/ana.24954

5. Olsson B, Portelius E, Cullen NC, et al. Association of cerebrospinal fluid neurofilament light protein levels with cognition in patients with dementia, motor neuron disease, and movement disorders. JAMA Neurol. 76(3):31825. https://doi.org/10.1001/jamaneurol.2018.3746.

6. Preische O, Schultz SA, Apel A, et al. Serum neurofilament dynamics predicts neurodegeneration and clinical progression in presymptomatic Alzheimer's disease. Nat Med. 2019;25(2):277-83. https://doi.org/10.1038/ s41591-018-0304-3.

7. Mattsson N, Andreasson U, Zetterberg H, Blennow K, Alzheimer's Disease Neuroimaging Initiative. Association of plasma neurofilament light with neurodegeneration in patients with Alzheimer disease. JAMA Neurol. 2017; 74(5):557-66. https://doi.org/10.1001/jamaneurol.2016.6117.

8. Lista S, Toschi N, Baldacci F, et al. Diagnostic accuracy of CSF neurofilament light chain protein in the biomarker-guided classification system for
Alzheimer's disease. Neurochem Int. 2017;108:355-60. https://doi.org/10. 1016/j.neuint.2017.05.010.

9. Lin Y, Lee W, Wang S, et al. Levels of plasma neurofilament light chain and cognitive function in patients with Alzheimer or Parkinson disease. Sci Rep. 2019;8(1):17368. https://doi.org/10.1038/s41598-018-35766-w.

10. Massa F, Meli R, Morbelli S, Nobili F, Pardini M. Serum neurofilament light chain rate of change in Alzheimer's disease: potentials applications and notes of caution. Ann Transl Med. 2019;7(Suppl 3):S133. https://doi.org/10. 21037/atm.2019.05.81.

11. Sernagor E, Eglen SJ, Wong ROL. Development of retinal ganglion cell structure and function. Prog Retin Eye Res. 2010;20(2):139-74. https://doi. org/10.1016/S1350-9462(00)00024-0.

12. Cooper LS, Wong TY, Klein R, Sharrett AR, Bryan RN, Hubbard LD, Couper DJ, Heiss G, Sorlie PD. Retinal microvascular abnormalities and MRI-defined subclinical cerebral infarction: the Atherosclerosis Risk in Communities Study. Stroke. 2006;37(1):82-6. https://doi.org/10.1161/01.STR.0000195134. 04355.e5.

13. Hong JT, Chae JB, Lee JY, et al. Ocular involvement in patients with primary CNS Iymphoma. J Neurooncol. 2011;102(1):139-45. https://doi.org/10.1007/ s11060-010-0303-9.

14. Sen HN, Bodaghi B, Hoang PL, Nussenblatt R. Primary intraocular lymphoma: diagnosis and differential diagnosis. Ocul Immunol Inflamm. 2009;17(3):13341. https://doi.org/10.1080/09273940903108544.

15. Yen MY, Lui JH. Malignant lymphoma involving the optic nerve head and the retina. Ann Ophthalmol. 1985;17(11):697-700.

16. Hirai T, Ando Y, Yamura M, et al. Transthyretin-related familial amyloid polyneuropathy: evaluation of CSF enhancement on serial T1-weighted and fluid-attenuated inversion recovery images following intravenous contrast administration. Am J Neuroradiol. 2005;26(8):2043-8.

17. Lamba PA, Bhalla JS, Mullick DN. Ocular manifestations of tubercular meningitis: a clinic-biochemical study. J Pediatr Ophthalmol Strabismus. 1986:23(3):123-5.

18. Hersi M, Irvine B, Gupta P, Gomes J, Birkett N, Krewski D. Risk factors associated with onset and progression of Alzheimer's disease: a systematic review of the evidence. Neurotoxicology. 2107;61:143-87. https://doi.org/10. 1016/.j.neuro.2017.03.006.

19. Zhang J, Chen C, Hua S, Liao H, Wang M, Xiong Y, Cao F. An updated metaanalysis of cohort studies: diabetes and risk of Alzheimer's disease. Diabetes Res Clin Pract. 2017;124:41-7. https://doi.org/10.1016/j.diabres.2016.10.024.

20. Lee CS, Larson EB, Gibbons LE, et al. Associations between recent and established ophthalmic conditions and risk of Alzheimer's disease. Alzheimers Dement. 2019;15(1):34-41. https://doi.org/10.1016/j.jalz.2018.06. 2856

21. Mancino R, Martucci A, Cesareo M, et al. Glaucoma and Alzheimer disease: one age-related neurodegenerative disease of the brain. Curr Neuropharmacol. 2018;16(7):971-7. https://doi.org/10.2174/ $1570159 \times 16666171206144045$.

22. Biscetti L, Luchetti E, Vergaro A, Menduno P, Cagini C, Parnetti L. Associations of Alzheimer's disease with macular degeneration. Front Biosci. 2017;9:174-91. https://doi.org/10.2741/e794.

23. Ohno-Matsui K, Akiba M, Moriyama M, Ishibashi T, Tokoro T, Spaide R. Imaging retrobulbar subarachnoid space around optic nerve by sweptsource optical coherence tomography in eyes with pathologic myopia. Invest Ophthalmol Vis Sci. 52(13):9644-50. https://doi.org/10.1167/iovs.118597

24. Wright LM, Stein TD, Jun $G$, et al. Association of cognitive function with amyloid- $\beta$ and tau proteins in the vitreous humor. J Alzheimers Dis. 2019; 68(4):1429-38. https://doi.org/10.3233/JAD-181104.

25. Oktem EO, Derle E, Kibaroglu S, Oktem C, Akkoyun I, Can U. The relationship between the degree of cognitive impairment and retinal nerve fiber layer thickness. Neurol Sci. 2015;36(7):1141-6. https://doi.org/10.1007/s10072-0142055-3.

26. Cheung CY, Ong YT, Hilal S, et al. Retinal ganglion cell analysis using highdefinition optical coherence tomography in patients with mild cognitive impairment and Alzheimer's disease. J Alzheimers Dis. 2015;45(1):45-56. https://doi.org/10.3233/JAD-141659.

27. den Haan J, Verbraak FD, Visser PJ, Bouwman FH. Retinal thickness in Alzheimer's disease: a systematic review and meta-analysis. Alzheimers Dement (Amst). 2017;6:162-70. Published 2017 Jan 25. https://doi.org/10. 1016/j.dadm.2016.12.014 
28. Cunha LP, Lopes LC, Costa-Cunha LV, et al. Macular thickness measurements with frequency domain-OCT for quantification of retinal neural loss and its correlation with cognitive impairment in Alzheimer's disease. PLoS One. 2016;11(4):e0153830. Published 2016 Apr 22. https://doi.org/10.1371/journal. pone. 0153830

29. Garcia-Martin ES, Rojas B, Ramirez Al, et al. Macular thickness as a potential biomarker of mild Alzheimer's disease. Ophthalmology. 2014;121(5):1149-51. https://doi.org/10.1016/j.ophtha.2013.12.023.

30. den Haan J, Janssen SF, van de Kreeke JA, Scheltens P, Verbraak FD, Bouwman FH. Retinal thickness correlates with parietal cortical atrophy in early-onset Alzheimer's disease and controls. Alzheimers Dement (Amst). 2017;10:49-55. Published 2017 Nov 6. https://doi.org/10.1016/j.dadm.2017. 10.005 .

31. Garcia-Martin E, Bambo MP, Marques ML, et al. Ganglion cell layer measurements correlate with disease severity in patients with Alzheimer's disease. Acta Ophthalmol. 2016;94(6):e454-9. https://doi.org/10.1111/aos. 12977.

32. Cunha JP, Proença R, Dias-Santos A, et al. OCT in Alzheimer's disease: thinning of the RNFL and superior hemiretina. Graefes Arch Clin Exp Ophthalmol. 2017;255(9):1827-35. https://doi.org/10.1007/s00417-017-37159.

33. Kwon JY, Yang JH, Han JS, Kim DG. Analysis of the retinal nerve fiber layer thickness in Alzheimer disease and mild cognitive impairment. Korean J Ophthalmol. 2017;31(6):548-56. https://doi.org/10.3341/kjo.2016.0118.

34. Liu S, Ong YT, Hilal S, et al. The association between retinal neuronal layer and brain structure is disrupted in patients with cognitive impairment and Alzheimer' disease. J Alzheimers Dis. 2016;54(2):585-95. https://doi.org/10. 3233/JAD-160067.

35. Cunha JP, Proença R, Dias-Santos A, et al. Choroidal thinning: Alzheimer's disease and aging. Alzheimers Dement (Amst). 2017;8:11-7. Published 2017 Mar 30. https://doi.org/10.1016/j.dadm.2017.03.004.

36. Trebbastoni A, Marcelli M, Mallone F, et al. Attenuation of choroidal thickness in patients with Alzheimer disease: evidence from an Italian prospective study. Alzheimer Dis Assoc Disord. 2017;31(2):128-34 0.1097/ WAD.0000000000000176.

37. Bayhan HA, Aslan Bayhan S, Celikbilek A, Tanık N, Gürdal C. Evaluation of the chorioretinal thickness changes in Alzheimer's disease using spectraldomain optical coherence tomography. Clin Exp Ophthalmol. 2015;43(2): 145-51. https://doi.org/10.1111/ceo.12386.

38. Gharbiya M, Trebbastoni A, Parisi F, et al. Choroidal thinning as a new finding in Alzheimer's disease: evidence from enhanced depth imaging spectral domain optical coherence tomography. J Alzheimers Dis. 2014; 40(4):907-17. https://doi.org/10.3233/JAD-132039.

39. O'Bryhim BE, Apte RS, Kung N, Coble D, Van Stavern GP. Association of preclinical Alzheimer disease with optical coherence tomographic angiography findings. JAMA Ophthalmol. 2018;136(11):1242-8. https://doi. org/10.1001/jamaophthalmol.2018.3556.

40. Querques G, Borrelli E, Sacconi R, et al. Functional and morphological changes of the retinal vessels in Alzheimer's disease and mild cognitive impairment. Sci Rep. 2019;9(1):63. Published 2019 Jan 11. https://doi.org/10. 1038/s41598-018-37271-6.

41. Lahme L, Esser EL, Mihailovic N, et al. Evaluation of ocular perfustion in Alzheimer's disease using optical coherence tomography angiography. J Alzheimers Dis. 2018;66(4):1745-52. https://doi.org/10.3233/JAD-180738.

42. Zhang YS, Zhou N, Knoll BM, et al. Parafoveal vessel loss and correlation between peripapillary vessel density and cognitive performance in amnestic mild cognitive impairment and early Alzheimer's disease on optical coherence tomography angiography. PLoS One. 2019;14(4):e0214685. https://doi.org/10.1371/journal.pone.0214685.

43. Mardin CY, Hosari S. Optical coherence tomography angiography in neuronal diseases: preliminary findings. Ophthalmologe. 2019;116(8):714-21. https://doi.org/10.1007/s00347-019-0883-5.

44. van de Kreeke JA, Nguyen HT, Konijnenberg E, et al. Optical coherence tomography angiography in preclinical Alzheimer's disease. $\mathrm{Br} J$ Ophthalmol. 2020;104(2):157-61. https://doi.org/10.1136/bjophthalmol-2019314127.

45. Yoon SP, Grewal DS, Thompson AC, et al. Retinal microvascular and neurodegenerative changes in Alzheimer's disease and mild cognitive impairment compared with control participants. Ophthalmol Retina. 2019; 3(6):489-99. https://doi.org/10.1016/j.oret.2019.02.002.
46. Zabel P, Kaluzny JJ, Wilkosc-Debczynska M, et al. Comparison of retinal microvasculature in patients with Alzheimer's disease and primary openangle glaucoma by optical coherence tomography angiography. Invest Ophthalmol Vis Sci. 2019;60(10):3447-55. https://doi.org/10.1167/iovs.1927028.

47. Grewal DS, Fine HF, Fekrat S. Is OCT angiography useful in neurodegenerative diseases? Ophthalmic Surg Lasers Imaging Retina. 2019; 50(5):269-73. https://doi.org/10.3928/23258160-20190503-02.

48. Grewal DS, Polascik BW, Hoffmeyer GC, Fekrat S. Assessment of differences in retinal microvasculature using OCT angiography in Alzheimer's disease: a twin discordance report. Ophthalmic Surg Lasers Imaging Retina. 2018;49(6): 440-4. https://doi.org/10.3928/23258160-20180601-09.

49. Yoon SP, Thompson AC, Polascik BW, et al. Correlation of OCTA and volumetric MRI in mild cognitive impairment and Alzheimer's disease. Ophthalmic Surg Lasers Imaging Retina. 2019;50(11):709-18. https://doi.org/ 10.3928/23258160-20191031-06.

50. Lee CS, Apte RS. Retinal biomarkers of Alzheimer's disease. Am J Ophthalmol. 2020 S0002-9394(20)30226-9. doi: https://doi.org/10.1016/j.ajo. 2020.04.040.

51. Jack CR Jr, Bennett DA, Blennow K, Carrillo MC, Feldman HH, Frisoni GB, Hampel $H$, Jagust WJ, Johnson KA, Knopman DS, Petersen RC, Scheltens $P$, Sperling RA, Dubois B. A/T/N: an unbiased descriptive classification scheme for Alzheimer's disease biomarkers. Neurology. 2016;87:539-47.

52. Zetterberg $\mathrm{H}$, Blennow K. From cerebrospinal fluid to blood: the third wave of fluid biomarkers for Alzheimer's disease. J Alzheimers Dis. 2018;64(s1): S271-9. https://doi.org/10.3233/JAD-179926.

53. Schindler SE, Bollinger JG, Ovod V, et al. High-precision plasma beta-amyloid 42/40 predicts current and future brain amyloidosis. Neurology. 2019;93: e1647-e59.

54. Karikari TK, Pascoal TA, Ashton NJ, et al. Blood phosphorylated tau 181 as a biomarker for Alzheimer's disease: a diagnostic performance and prediction modelling study using data from four prospective cohorts. Lancet Neurol. 2020;19:422-33.

55. Abu-Rumeileh S, Capellari S, Stanzani-Maserati M, et al. The CSF neurofilament light signature in rapidly progressive neurodegenerative dementias. Alz Res Therapy. 2018;10:Article no. 3. https://doi.org/10.1186/ s13195-017-0331-1.

56. $\mathrm{Hu} \mathrm{H}$, Chen $\mathrm{KL}, \mathrm{Ou}$ YN, et al. Neurofilament light chain plasma concentration predicts neurodegeneration and clinical progression in nondemented elderly adults. Aging (Albany NY). 2019;11(17):6904-14. https://doi.org/10.18632/aging.102220.

57. Lewczuk P, Ermann N, Andreasson U, et al. Plasma neurofilament light as a potential biomarker of neurodegeneration in Alzheimer's disease. Alzheimers Res Ther. 2018;10(1):71. Published 2018 Jul 28. https://doi.org/10. 1186/s13195-018-0404-9.

58. Jin M, Cao L, Dai YP. Role of neurofilament light chain as a potential biomarker for Alzheimer's disease: a correlative meta-analysis. Front Aging Neurosci. 2019;11:254. Published 2019 Sep 13. https://doi.org/10.3389/fnagi. 2019.00254

59. Hampel H, Toschi N, Baldacci F, Alzheimer Precision Medicine Initiative (APMI), et al. Alzheimer's disease biomarker-guided diagnostic workflow using the added value of six combined cerebrospinal fluid candidates: $A \beta_{1-42}$, total-tau, phosphorylated-tau, NFL, neurogranin, and YKL-40. Alzheimers Dement. 2018;14(4):492-501. https://doi.org/10.1016/j.jalz.2017. 11.015 .

60. Mattsson N, Insel PS, Palmqvist S, et al. Cerebrospinal fluid tau, neurogranin, and neurofilament light in Alzheimer's disease. EMBO Mol Med. 2016;8(10): 1184-96. Published 2016 Oct 4. https://doi.org/10.15252/emmm.201606540.

61. Dhiman K, Blennow K, Zetterberg H, Martins RN, Gupta VB. Cerebrospinal fluid biomarkers for understanding multiple aspects of Alzheimer's disease pathogenesis. Cell Mol Life Sci. 2019;76(10):1833-63. https://doi.org/10.1007/ s00018-019-03040-5.

62. Lista S, Toschi N, Baldacci F, et al. Diagnostic accuracy of SCF neurofilament light chain protein in the biomarker-guided classification system for Alzheimer's disease. Neurochem Int. 2017;108:355-60. https://doi.org/10. 1016/j.neuint.2017.05.010.

63. Chidlow G, Osborne NN. Rat retinal ganglion cell loss caused by kainate, NMDA and ischemia correlates with a reduction in mRNA and protein of Thy-1 and neurofilament light. Brain Res. 2003;963(1-2):298-306. https://doi. org/10.1016/S0006-8993(02)04052-0. 
64. Taniguchi T, Shimazawa M, Hara H. Alterations in neurofilament light in optic nerve in rat kainate and monkey ocular hypertension models. Brain Res. 2004;(2):1013, 241-8. https://doi.org/10.1016/S0006-8993(02)04052-0.

65. Sasaoka M, Taniguchi T, Shimazawa M, Ishida N, Shimazaki A, Hara H. Intravitreal injection of endothelin-1 caused optic nerve damage following to ocular hypoperfusion in rabbits. Exp Eye Res. 2006;83(3):629-37. https:// doi.org/10.1016/j.exer.2006.03.007

66. Balaratnasingam C, Morgan WH, Bass L, Kang M, Cringle SJ, Yu DY. Timedependent effects of focal retinal ischemia on axonal cytoskeleton proteins. Invest Ophthalmol Vis Sci. 2010;51(6):3019-28. https://doi.org/10.1167/iovs. 09-4692.

67. Kamalden TA, Ji D, Fawcett RJ, Osborne NN. Genistein blunts the negative effect of ischaemia to the retina caused by an elevation of intraocular pressure. Ophthalmic Res. 2011;45(2):65-72. https://doi.org/10.1159/ 000313985.

68. Modvig S, Degn M, Sander B, et al. Cerebrospinal fluid neurofilament light chain levels predict visual outcomes after optic neuritis. Mult Scler. 2016 Apr;22(5):590-8. https://doi.org/10.1177/1352458515599074.

69. Schmidt KG, Bergert $H$, Funk RH. Neurodegenerative diseases of the retina and potential for protection and recovery. Curr Neuropharmacol. 2008;6(2): 164-78. https://doi.org/10.2174/157015908784533851.

70. Prakasam A, Muthuswamy A, Ablonczy Z, et al. Differential accumulation of secreted ABPP metabolites in ocular fluids. J Alzheimers Dis. 2010;20(4): 1243-53. https://doi.org/10.3233/JAD-2010-100210.

71. More Swati S, Robert V. Hyperspectral imaging signatures detect amyloidopathy in Alzheimer's mouse retina well before onset of cognitive decline. ACS Chem Neurosci. 2015;6(2):306-15. https://doi.org/10.1021/ cn500242z.

72. Zheng C, Zhou XW, Wang JZ. The dual roles of cytokines in Alzheimer's disease: update on interleukins, TNF- $\alpha$, TGF- $\beta$ and IFN- $\gamma$. Transl Neurodegener. 2016;5:7. https://doi.org/10.1186/s40035-016-0054-4.

73. Chen X, Hu Y, Cao Z, Liu Q, Cheng Y. Cerebrospinal fluid inflammatory cytokine aberrations in Alzheimer's disease, Parkinson's disease and amyotrophic lateral sclerosis: a systematic review and meta-analysis. Front Immunol. 2018;9:2122. https://doi.org/10.3389/fimmu.2018.02122.

74. Li DW, Ren H, Jeromin A, et al. Diagnostic performance of neurofilaments in Chinese patients with amyotrophic lateral sclerosis: a prospective study. Front Neurol. 2018:9:726. https://doi.org/10.3389/fneur.2018.00726.

75. Westin K, Buchhave P, Nielsen H, Minthon L, Janciauskiene S, Hansson O. CCL2 is associated with a faster rate of cognitive decline during early stages of Alzheimer's disease. PLoS One. 2012;7(1):e30525. https://doi.org/10.1371/ journal.pone.0030525.

76. Tripathy D, Thirumangalakudi L, Grammas P. Expression of macrophage inflammatory protein 1-a is elevated in Alzheimer's vessels and regulated by oxidative stress. J Alzheimer's Dis. 2007;11(4):447-55. https://doi.org/10.3233/ JAD-2007-11405.

77. Kim H, Shin A, Lee KJ. Differences in C-reactive protein level in patients with Alzheimer's disease and mild cognitive impairment. J Psychiatry. 2015;18(1): Psychiatry-14-Psychiatry155. doi: 18:1.https://doi.org/10.4172/1994-8220. 1000194.

78. Cipollini V, Troili F, Giubilei F. Emerging biomarkers in vascular cognitive impairment and dementia: from pathophysiological pathways to clinical application. Int J Mol Sci. 2019;20(11):2812. https://doi.org/10.3390/ ijms20112812.

79. Sabe L, Jason L, Juejati M, Leiguarda R, Starkstein S. Sensitivity and specificity of the Mini-Mental State Exam in the diagnosis of dementia. Behav Neurol. 1993;6(4):207-10. https://doi.org/10.3233/BEN-1993-6405.

\section{Publisher's Note}

Springer Nature remains neutral with regard to jurisdictional claims in published maps and institutional affiliations.

Ready to submit your research? Choose BMC and benefit from:

- fast, convenient online submission

- thorough peer review by experienced researchers in your field

- rapid publication on acceptance

- support for research data, including large and complex data types

- gold Open Access which fosters wider collaboration and increased citations

- maximum visibility for your research: over $100 \mathrm{M}$ website views per year

At BMC, research is always in progress.

Learn more biomedcentral.com/submissions 